\title{
Termination Risk and Agency Problems: Evidence from the NBA
}

\section{Citation}

Alma Cohen, Nadav Levy \& Roy Sasson, Termination Risk and Agency Problems: Evidence from the NBA, (Harv. John M. Olin Discussion Paper Series No. 819, Apr. 2015).

\section{Permanent link}

http://nrs.harvard.edu/urn-3:HUL.InstRepos:16076105

\section{Terms of Use}

This article was downloaded from Harvard University's DASH repository, and is made available under the terms and conditions applicable to Open Access Policy Articles, as set forth at http:// nrs.harvard.edu/urn-3:HUL.InstRepos:dash.current.terms-of-use\#OAP

\section{Share Your Story}

The Harvard community has made this article openly available.

Please share how this access benefits you. Submit a story.

\section{Accessibility}


ISSN 1936-5349 (print)

ISSN 1936-5357 (online)

\section{HARVARD}

JOHN M. OLIN CENTER FOR LAW, ECONOMICS, AND BUSINESS

TERMINATION RISK AND AGENCY PROBLEMS:

EVIDENCE FROM THE NBA

Alma Cohen

Nadav Levy

Roy Sasson

Discussion Paper No. 819

$4 / 2015$

Harvard Law School

Cambridge, MA 02138

This paper can be downloaded without charge from:

The Harvard John M. Olin Discussion Paper Series:

http://www.law.harvard.edu/programs/olin_center/

The Social Science Research Network Electronic Paper Collection:

http://ssrn.com/abstract=2589561 


\title{
Termination Risk and Agency Problems: Evidence from the NBA*
}

\author{
Alma Cohen, ${ }^{\mathfrak{t}}$ Nadav Levy, ${ }^{\ddagger}$ and Roy Sasson ${ }^{\mathrm{s}}$
}

\begin{abstract}
$\underline{\text { Abstract }}$
When agents face a risk of termination by the principal in the short term, they may underinvest in projects whose results would be realized only in the long term. We use data on decisions made by NBA coaches to study how risk of termination by the principal affects the behavior of agents. Because letting a rookie play produces long-term benefits on which coaches with a shorter investment horizon might place lower weight, we hypothesize that higher termination risk might lead to lower rookie participation. Consistent with this hypothesis, we find that, during the period of the NBA's 1999 collective bargaining agreement (CBA) and controlling for the characteristics of rookies and their teams, higher termination risk was associated with lower rookie participation and that this association was driven by important games. We also find that the association does not exist for second-year players and that the identified association disappeared when the 2005 CBA gave team owners stronger incentives to monitor the performance of rookies and preclude their underuse.
\end{abstract}

JEL Classification: D20, J44, K00, L83

\footnotetext{
* We would like to thank Lucian Bebchuk, Liran Einav, Yaniv Grinstein, Saul Lach, Yona Rubinstein, Analia Schlosser, Charles Wang and workshop participants at Harvard, Hebrew University, Tel Aviv University, and IDC for helpful comments and conversations, and Zvika Messing for valuable research assistance.

${ }^{t}$ Harvard Law School, Tel-Aviv University, and NBER

${ }^{\text {}}$ Interdisciplinary Center (IDC)

${ }^{s}$ Tel-Aviv University
} 


\section{Introduction}

When agents fear termination by the principal, agency problems can be expected to occur. When making decisions, such agents might engage in short-termism, underinvesting in projects whose payoffs would be partly realized only in the long term. ${ }^{1}$ This paper investigates this agency problem empirically using data about decisions that National Basketball Association (NBA) coaches made regarding the allocation of playing time to first-year players (rookies). The NBA data enable us to use rich sets of controls as well as variation in both the relative significance of short-term and long-term payoffs and the oversight by principals in order to estimate coaches' risk of termination and investigate how that risk relates to rookie participation. ${ }^{2}$ Our findings are consistent with the hypothesis that, controlling for the characteristics of rookies and teams, high termination risk is associated with lower rookie participation and lower investment in rookies' human capital. Furthermore, both the existence and the strength of this association depend on several factors that are consistent with shorttermism by coaches with high termination risk.

Because NBA rookies are restricted to stay with the team that signed them for at least four years unless the team chooses to release them, letting rookies play provides the team with longterm benefits that go beyond the current NBA season: it not only improves the rookies' ability to play in the NBA setting but also enables coaches to gain information about the rookies that will be useful in future contract decisions. For this reason, there might be circumstances in which letting a rookie play is optimal from the perspective of the team's owner even if it might not be beneficial to the team's current standings. To the extent that coaches have some discretion in making rookie participation decisions, a coach who faces a high termination risk, and who therefore places less weight on the team's performance beyond the current season, can be expected, other things being equal, to play rookies less frequently.

\footnotetext{
${ }^{1}$ For models of agency problems that result when agents face termination risk or otherwise have short time horizons, see Narayanan (1985); Stein (1988, 1989); Bebchuk and Stole (1993); Von Thadden (1995); and Bolton, Scheinkman, and Xiong (2006).

${ }^{2}$ The rich datasets available for professional sports have been noticed by economists, and a significant number of papers have conducted empirical economic analyses using such datasets. See, e.g., Hausman and Leonard (1997), Kahn (2000), Chiappori et al. (2002), Duggan and Levitt (2002), Garicano et al. (2005), Romer (2006), Price and Wolfers (2010), Parson et al. (2011), Abramitzky et al. (2012) and Kahane et al. (2013).
} 
Our analysis initially focuses on decisions made by NBA coaches over the five-year period governed by the 1999 collective bargaining agreement (CBA). During this period, rookies were given three-year contracts, which teams were not permitted to shorten but could, at the end of the second year, choose not to extend for a fourth year. We find that coaches who faced a higher risk of termination-and thus a smaller likelihood of being able to benefit from the long-term consequences of giving rookies more playing experience-are associated with a lower use of rookies to an extent that is both statistically significant and economically meaningful. In identifying this association, we control for the characteristics and past performances of the rookies and their teams given that, as we show, termination risk is at least partly due to exogenous factors.

We next examine which types of games drive the identified association between the termination risk of a coach and lower rookie participation. To the extent that the association reflects an agency problem involving an overvaluation of short-term consequences, the association can be expected to be more pronounced in situations where the short-term costs of playing rookies are higher. The NBA data provide us with substantial variation between games that were and were not important. We therefore expect, and the data confirm, that the association between termination risk and lower rookie participation is especially pronounced in games that are important for the team's chances of getting into the current season's playoffs.

We examine additional two settings where we expect the identified association to be weaker or even nonexistent. First, there is substantial empirical work to suggest that the extent to which agents' behavior is characterized by an undervaluation of long-term consequences (shorttermism) depends on the nature and intensity of team owner oversight (Asker et al. 2014; Bernstein 2012; Gonzalez and André 2012). Our dataset enables us to examine the effects of a possible change in team owner oversight or even intervention on the use of rookies. Unlike the CBA of 1999, the 2005 CBA provided teams with the option of deciding at the end of a rookie's first year to shorten his contract from three years to two years. We conjecture that, while team owners commonly leave rookie playing decisions to coaches, they take special interest in decisions about whether to retain or trade rookies. Therefore, before such decisions are made, team owners seek to ensure that rookies get opportunities to play during the year even if coaches have incentives to underuse them. We indeed find that, during the period of the 2005 CBA, the association between termination risk and lower rookie participation ceased to exist. 
Second, we expect that when NBA rookies become second-year players with a year of professional experience behind them, the marginal long-term benefit of providing them with additional experience declines on average, as does the marginal short-term cost of letting them play. In addition, team owners, who have a special interest in player retention decisions, have incentives to exercise tighter oversight to ensure that second-year players get adequate playing opportunities. We indeed find that, during the same period in which termination risk was associated with lower rookie participation, no such association existed with regard to secondyear players. Thus, in addition to the basic finding of an association between termination risk and lower use of rookies, we have a significant set of additional findings that are all consistent with a short-termism story.

Much of the empirical literature on short-termism has focused on the investment decisions of CEOs of public companies and on how their decisions compare with those of CEOs of private companies (see, e.g., Dechow and Sloan 1991; Xu 2012; Aghion et al. 2010; Edmans et al. 2013; Ladika and Sautner 2013; and Asker et al. 2014). However, with the important exception of Azoulay, Manso and Zivin (2011), who focus on investments by medical researchers in longterm risky projects, there is little work on short-termism in other contexts, and our paper highlights the potential value of studying such contexts.

The remainder of our paper is organized as follows. Section II describes the relevant institutional background concerning the NBA and its teams, rookie players, coaches, and CBAs. Section III describes our data. Section IV estimates the termination risk of coaches and the importance of games. Section V tests our hypothesis concerning the relationship between coach termination risk and rookie participation. Section VI tests our hypotheses concerning the circumstances in which higher termination risk of NBA coaches should not be expected to be correlated with lower rookie participation; it also documents our robustness tests. Section VII presents our conclusion.

\section{Institutional Background}

The NBA is the leading professional basketball league in North America. There are thirty teams in the league, divided into an Eastern Conference and a Western Conference. Each team has a roster of twelve to fifteen players. We focus in this paper on first-round rookies-players in 
the first year of their NBA contracts-and follow them through their second year in the NBA. During the period that we examine, there were, on average, twenty-seven to twenty-eight rookies in the NBA and about the same number of second-year players each year.

\section{A. NBA Rookies, Games, and Coaches}

Rookies enter the NBA largely through the draft. The draft consists of two rounds, during which the teams take turns selecting rookies. Thirty rookies are chosen in each round. Firstround picks are allocated to teams according to a set procedure that is designed to give an advantage to teams that did not fare well in the preceding season. ${ }^{3}$

Our study focuses on first-round rookies because such rookies, unlike second-round picks, are guaranteed contracts whose terms are exogenously determined throughout the period of each CBA. That is, each first-round rookie gets a contract for the same period and is paid according to a predetermined scale that decreases with the rookie's draft rank.

As can be expected, there is a negative correlation between a team's record in the previous year and its rookies' draft rank in the first round. However, this negative correlation is not perfect for two reasons: first, the top three teams to pick rookies are determined by a lottery; second, teams often trade current or future draft picks in exchange for veteran players, cash, or some other consideration. During the period that we study, 1999-2010, the correlation between draft ranking and team ranking in the previous season was -0.45 .

The NBA season is divided into the regular season and the playoffs. During the regular season, each team participates in eighty-two games, facing each of the other twenty-nine teams in the league three to four times. At the end of the regular season, the eight teams with the best win-loss record from each conference go to the playoffs and compete for the championship in an elimination tournament. Thus, the threshold for entering the playoffs is holding the eighth position in the conference. Our empirical analysis focuses on regular-season games because, during this period, all teams play the same number of games and play against each of the other teams.

\footnotetext{
${ }^{3}$ The procedure operates as follows: first, the rights for the first three draft picks are allocated through a lottery among the fourteen nonplayoff teams. This lottery is weighted so that the team with the lowest rating during the previous season has the highest chance of obtaining the first draft pick. Picks 4-14 are then allocated among the remaining nonplayoff teams in reverse order of their previous season's performance. Picks 15-30 are allocated among the remaining sixteen teams in reverse order of their previous season ratings. Picks 31-60 belong to the second round and are also granted to the teams in reverse order of their previous season's ranking.
} 
The owner of the team, and the general manager working on the owner's behalf, hire the team's head coach as well as make decisions to hire players, renew their contracts, or trade them. However, the head coach generally makes the tactical decisions involved in the team's games, including decisions about whether to let rookies play in any given game. Although owners (and the general managers working on their behalf) tend to leave substantial discretion to the coaches, they have the power to fire the coaches and thus have the ability (which they may or may not use) to intervene and influence their coaches' decisions with respect to issues that they deem important.

\section{B. The Collective Bargaining Agreement}

Each CBA defines the framework for contracts with players and all other labor-related transactions during the period it governs. About every five years, NBA team owners and the National Basketball Player's Association, which is the union for the league's professional basketball players, bargain over a new CBA.

Our study covers the periods governed by the CBAs of 1999 and 2005. Under these two CBAs, teams guaranteed their chosen first-round rookies a two-year contract in 1999 and a threeyear contract in 2005 with a fixed salary that was based on the player's draft rank and year of tenure. In describing the two CBAs below, we focus on their provisions concerning rookies. These two agreements also had provisions governing the treatment of veteran players, ${ }^{4}$ but these provisions are not practically relevant for the subject at hand.

\section{The 1999 CBA}

During the period of the preceding CBA (1995-1998), weak teams kept losing their best rookies to strong teams after the rookies' three-year contracts ended. Banaian and Gallagher (1999) document that, out of the top twelve picks in the 1995 draft, only two rookies remained with their original teams. This pattern reduced the teams' incentives to invest in training talented young rookies. The 1999 CBA addressed this problem by introducing changes that enabled

\footnotetext{
${ }^{4}$ Both the 1999 and the 2005 CBAs imposed a salary cap on the salaries of veteran players. They also applied a team luxury tax, a penalty paid by high-spending teams that exceeded the team's salary cap. However, the two CBAs differed in how they allocated basketball-related income (BRI) between players and team owners: players received 48\% of BRI under the 1999 CBA but only 57\% of BRI under the 2005 CBA.
} 
teams to benefit for a longer period from their investment in rookies. In particular, the 1999 CBA extended the length of first-round rookie contracts from three years to four, providing a salary scale for the fourth year as well as for the first three. This change enabled teams to keep their star rookies for an additional year for relatively low pay. ${ }^{5}$

To avoid scenarios whereby teams were bound to pay salaries to nonproductive players for four years, the 1999 CBA also introduced a team-option clause in rookie contracts. This option allowed teams to choose at the end of the contract's second year to "waive," without bearing any costs, the fourth contract year of a nonproductive player. Having the right but not the obligation to use a player for a fourth year provided teams with a valuable unilateral option, and teams made use of this option. Out of the 152 first-round rookies drafted under the 1999 CBA for whom data are available concerning their second NBA year, 35 (23\%) had their contracts waived before their fourth year. ${ }^{6}$

\section{The 2005 CBA}

The 2005 CBA, which governed rookies drafted between 2005 and 2010, retained the basic elements of the 1999 CBA with respect to the contracts offered to first-round rookies. However, it made one change that could have had an impact on behavior: it added another team-option clause concerning whether the rookie would play with the team upon reaching his third year. Teams were able to exercise this option only at the end of the rookie's first year. Thus, under the 2005 CBA, teams were able to waive unwanted players earlier than before, depending on the rookie’s performance during his first year. Out of 116 first-round rookies drafted under the 2005 CBA for whom data are available concerning their second NBA year, 11 (9.5\%) were waived from their fourth year, with the decision made after the second year, and 9 others (6.5\%) were waived from their third year, with the decision made after the first year.

\footnotetext{
${ }^{5}$ An additional change further helped teams capture long-term benefits from investing in a rookie's human capital. After reaching his fifth year, a player became a "restricted free agent" and not a free agent as in the previous CBA. By giving the player a one-year qualifying offer, the team kept the rights to match the best offer that the player received from another team, and if it did match that offer, the player had to stay with the team. This option further increased the ability of teams to benefit in the long term from investing in a rookie's human capital.

${ }^{6}$ Information concerning which players were waived was collected by hand from the NBA's official website, which tracks and publishes all NBA transactions and player mobility.
} 
The CBA of 2005 also addressed the issue of players skipping college and going directly to the NBA. ${ }^{7}$ It introduced a new age limit specifying that drafted players, both foreign and American, must be at least nineteen years of age at the draft year and that American players must have at least one year behind them since graduating from high school.

\section{The Data}

Our data consist of all rookies who played in the NBA in regular-season games during the period of 1999-2010, the years governed by the 1999 and 2005 CBAs. As there are 82 games during a regular season and we followed each rookie through his first and second years in the NBA, our data contain a maximum of 164 games for each player. For each player and each game, we have substantial information, including the player's characteristics and performance statistics, the player's team and coach, and the opposing team. As described below, we obtained most of our data from Basketball-Reference.com, a site that provides statistical data on every player and game in the NBA since 1945, and we supplemented these data with hand-collected information.

Rookie Characteristics: Rookies' characteristics were obtained from BasketballReference.com player-level data. For each rookie we have information about his draft year, draft ranking, position played, years spent in college, ${ }^{8}$ age, and salary.

For the vast majority of rookies, we have information about their first two full seasons with the NBA. ${ }^{9}$ We excluded from our data six rookies who were sent by their NBA teams to spend

\footnotetext{
${ }^{7}$ The 1995 CBA made it economically more advantageous for star rookies to try to put their rookie years behind them and reach the far more lucrative NBA years as soon as possible (See, e.g., the CNN online article "How to End the Flood of NBA Teens," April 2005, http://money.cnn.com/2005/04/29/commentary/column_sportsbiz/sportsbiz/). Moreover, the introduced scale for rookies' salaries reduced the cost of using rookies and made teams more willing to take chances on those without the full college experience (see "How the NBA Turned a Trickle of Underclassmen Leaving School Early Into a Flood,” by Dan T. Rosenbaum, Dept. of Economics: University of North Carolina-Greensboro; September 2003). The adoption of the 1995 CBA was indeed followed by an increase in the incidence of rookies choosing to drop out of college, or to skip college altogether, to join the NBA (see Groothuis, Hill, and Perry 2007).

${ }^{8}$ About $8 \%$ of all rookies in the sample skipped college. Among those who did not, the average number of years spent in college was about 2.1. Because of the age requirement introduced in the 2005 CBA, the incidence of rookies who skipped college was lower, and the average number of college years was higher, under the 2005 CBA than under the 1999 CBA.
} 
their entire first season playing at the development league and who joined the NBA only in their second year under the contract. Some rookies were traded during their first and/or second contract season. For purposes of our analysis, we included these players for only the two seasons in which they played for the same team. ${ }^{10}$

Rookie Participation and Performance: For each rookie, we obtained from BasketballReference.com player-season-game-level information on each regular-season game in which he played. This information consists of the number of minutes the rookie played in the game and his performance statistics, such as points scored, assists, rebounds, steals, turnovers, blocks, successful and unsuccessful free throws, and personal fouls. Using these statistics, we constructed a compound game-level performance measure for each game-rookie observation, as described below.

For each player in the player-season-level data, Basketball-Reference.com uses the different dimensions of season performance to produce a player efficiency rating (PER), which is a rating of a player's per minute productivity. This measure, which was developed in the late 1990s by John Hollinger, compiles all of the player's different performance dimensions during the season into one number, which is computed and reported only at the season level. To construct such a measure at the player-game level, we first regress PER on all the player's different performance dimensions at the season level (these measures explain PER almost entirely with an $R^{2}$ equal to 0.99) and then use the coefficients, obtained from the player-season-level data, to construct a PER using all the player's different performance dimensions at the game level.

Table 1 presents summary statistics for our sample. The main sample consists of more than 48,000 player-season-game observations involving 308 different rookies. Of these observations, 46\% were under the 1999 CBA and 54\% were under the 2005 CBA. The table provides summary statistics for the whole sample, as well as for four subsamples broken down by player tenure (rookies and second-year players) and by the two CBAs (1999 and 2005). On average, in

\footnotetext{
${ }^{9}$ After being drafted, twelve foreign rookies deferred the start of their NBA careers to play overseas. We followed these players during their first two years after they started playing in the NBA.

${ }^{10}$ For example, if a rookie was traded during the middle of his first season, we counted all the games for which he played for the team to which he was traded. If he was traded during his second season, we counted all the games for which he played for the first team. In total, our data include twenty-seven players, accounting for $8.5 \%$ of all rookies, who were traded during their first season or second season.
} 
our data, players played in about $73 \%$ of the regular-season games. This breaks down into $67 \%$ for rookies under the 1999 CBA and 75\% for each of the other subsamples.

The rookies' average PER was 11.7, and each rookie played an average of 16.2 minutes per game. The levels are lower for rookies than for second-year players, which might be at least partly attributable to the experience that second-year players obtained during their first NBA year. Differences among the subsamples with respect to the other variables are not statistically significant.

Team Ranking: We generated information about each team's ranking within its conference using Basketball-Reference.com season-game-level data. These data contain information about the date of the game, the home and visitor teams, and the final score. For each team in a given game, we generated a variable that indicates its conference ranking at the beginning of the game. For any given game in a particular season, we calculated each team's cumulative win-loss record to date and then compared it with those of the other teams in the same conference. We then ranked the teams from 1 to 16 (where 1 represents the highest ranking and 16 the lowest). Ties were broken in favor of the team that had more wins (mostly relevant when two teams had the same record but a different number of games played). In the first game of the season, we initialized this variable with the team's ranking at the end of the preceding regular season. We also obtained information about whether the team reached the playoffs.

Coach Data: Basketball-Reference.com also contains information on all NBA coaches during our period of examination. Our coach-season-game-level dataset includes information about all the NBA teams that the coach trained during his career, the number of regular-season wins and losses during his career, the number of playoff wins and losses during his career, and the age of the coach. ${ }^{11}$ For each coach in each season we calculated his cumulative career wins and losses up to the current season, his tenure with the NBA, and his tenure with his current team. For the period of our study, our data consist of 416 coach-season observations involving 111 different coaches.

Coaches' contracts are guaranteed for a specified number of years, and they generally do not tie coaches' pay to a season's results or a stake in the team. Information about the length of those contracts was obtained from various online sources. For $70 \%$ of our coach-season-level data, we

\footnotetext{
${ }^{11}$ Basketball-Reference.com did not have age data for 24 of the 111 coaches during the period of 19992010, so this information was collected from online articles and biographies of the coaches.
} 
found information on the length of the contract from "Weak Side Awareness," a blog that publishes various NBA statistics. ${ }^{12}$ The remaining $30 \%$ were hand-collected from various Internet resources and articles.

Information on whether coaches were fired or left their teams was also hand-collected from various Internet resources and articles. Of the 416 coach-season observations during the period of our study, 114 involved termination (i.e., firing) by the beginning of the subsequent year. Such firing accounted for $83 \%$ of coach-season observations in which the coach was not with the team at the beginning of the subsequent season. The $17 \%$ of coaches who left their teams before the beginning of the subsequent year without having been fired were, on average, seven years older that those who were fired, and their decision to leave often seemed to have been made for personal reasons.

Being fired appears to have significant adverse consequences for coaches. About $60 \%$ of fired coaches did not find a new head coach position within the NBA during the period that we studied. For the remaining $40 \%$ who did find a new coaching position in the NBA, it took them, on average, more than two years to find it.

Table 2 presents summary statistics for the coach-season-game level data, which includes a total of 29,110 observations. In 21\% of the coach-season-game observations, the coach was fired by the beginning of the next season. On average, coaches had 1.5 years left on their contracts, were 51 years of age, had 4.8 years of experience prior to joining the current team, and had a tenure of 2.7 years with the current team. As to their records, coaches had, on average, $37 \%$ of victories with the team from which they were fired.

\section{Estimating Termination Risk and Game Importance}

Our empirical analysis builds on our estimate of the termination risk of coaches and the importance of games. Below we begin by explaining how we estimated these two variables.

\footnotetext{
${ }^{12}$ For each coach-season, the blog provides a reference to an online source (usually an article) from which the information was extracted. This made it possible to double-check the accuracy of the contract data.
} 


\section{A. Termination Risk}

To predict coach termination risk, we matched our team-season-game data with coach characteristics data. Then, using our full dataset, we calculated for each coach in each game the probability of that coach being fired by the beginning of the next season. To do so, we estimate the following Probit model:

$$
\text { Coach Fired }_{c, t, s}=X_{c, t, s}^{\prime} \alpha+Z_{c, t, s, g}^{\prime} \beta+\delta_{t}+\varepsilon_{c, t, s, g}
$$

The dependent variable, Coach Fired ${ }_{c, t, s}$, is an indicator that is equal to 1 if coach $c$ was fired by his current team $t$ during or at the end of season $s$ and is equal to 0 otherwise. In the above model, $X_{c, t, s}$ is a vector of coach-team-season covariates, including number of years left in the coach's contract; the age and age squared of the coach; a dummy variable indicating whether the team is part of the Eastern Conference; the tenure and tenure squared of the coach in the NBA prior to his joining the current team; the tenure and tenure squared of the coach with his current team; the percentage of victories the coach had with the team; the percentage of victories the coach had prior to joining the team; a dummy variable indicating whether the coach has no tenure with the team; a dummy variable indicating whether the coach started coaching the team during the middle of the season; a dummy variable that is equal to 1 if the team reached the playoffs in the preceding season and equal to 0 otherwise; and the number of playoff wins during the preceding season.

$Z_{c, t, s, g}$ is a vector of game-specific covariates. These covariates include the number of games played so far in the season; the number of games directed by the current coach this season; the difference between the team's winning percentage at the current stage in the season and at the same stage in the preceding season; the interaction term between the two previous variables; and the predicted probability of the team entering the playoffs (as calculated in Subsection B below). Finally, $\delta_{t}$ is a vector of team-fixed effects.

Table 3 reports the results of this regression. The results indicate that the probability of the coach being fired decreases with the number of years left on his contract. Because coaches' contracts are guaranteed, a team that fires its coach before the contract ends has to pay the coach the reminder of his salary if he is not hired by another team or, if he is hired by another team at a lower salary, the excess of his salary over the lower salary with the other team. Therefore, the negative coefficient reflects the fact that the size of the severance payment that would have to be paid to the coach in the case of his being fired increases with the number of years left in his 
contract. In addition, the probability of termination decreases with the NBA experience that the coach has, the number of games in which he served as coach during the current season, and the difference between the team's current record and its record at the end of the previous season (which reflects the improvement in the team's performance during the current year under the coach's leadership). Using the Probit model shown above, we assign to each coach at the beginning of each game an estimate of his termination risk-that is, the probability of his being fired by the beginning of the next regular season.

We treat the number of years left on the coach's contract as exogenous to, and not a product of, subsequent decisions about whether to play rookies. We view this variable as exogenous because the number of years left is determined by the time passed since the start of the contract. It might be argued that the number of years left is not exogenous because teams that did not do well in previous seasons might give new coaches contracts of shorter duration and that the number of years left is therefore correlated with the length of the contract. To address this concern, we check, in an unreported regression, whether the performance of the team in the previous season is a predictor of the length of the coach's contract, and we find that it is not.

\section{B. Game Importance}

NBA teams compete in an annual championship. To be able to compete in the championship and reap the substantial additional monetary rewards from participating in playoff games, teams must first get into the playoffs, and that requires them to put forth their best efforts during the regular season.

We therefore construct a measure of game importance based on the expected marginal impact that a win in the next game would have on the odds of the team making the playoffs. To compute this measure, we begin by estimating the probability of teams making the playoffs at any particular point in time. Using team-season-game data, we estimate this probability by running the following Probit model for each team $t$, season $s$, and game number $g$ :

$$
\begin{aligned}
& \text { Playoff }_{t, s}=\alpha_{0}+\alpha_{1} \text { Conference Rank } k_{t, s, g}+\alpha_{2} \text { Games Played }_{t, s, g}+ \\
& +\alpha_{3} \text { Distance from } 8_{t, s, g}+\alpha_{4} \text { Games Played }{ }_{t, s, g} x \text { Distance from } 8_{t, s, g}+\varepsilon_{t, s}
\end{aligned}
$$

The dependent variable, Playoff $s_{t, s}$, is a dummy variable that is equal to 1 if the team reached the playoffs at the end of the regular season $s$ and is equal to 0 otherwise. For covariates, we use the following variables: Conference $\operatorname{Rank}_{t, s, g}$ indicates the ranking of the team in its 
conference at the beginning of the current game (as described in Section III); Games Played ${ }_{t, s, g}$ is the number of games played prior to the current game by team $t$; Distance from $8_{t, s, g}$ is the difference between the win-loss record of team $t$ and that of the team ranked eighth in the same conference prior to the current game; ${ }^{13}$ and Games Played ${ }_{t, s, g} x$ Distance from $8_{t, s, g}$ is an interaction term that captures the increasing effect of Distance from $8_{t, s, g}$ as the season progresses.

Table 4 reports the marginal effects evaluated at the means of our Probit model. Standard errors are clustered at the team level. As expected, the probability of reaching the playoffs increases with both the team's ranking in the conference at the time of the game and the gap between the team's record and the record of the eighth-ranked team in the conference at that time. Finally, the positive coefficient of the interaction term indicates that a given gap has an increasing effect as the regular season nears its end.

Our playoff-probability model performs well. For the entire sample, the count $R^{2}$ of the model equals 0.86 , indicating that $86 \%$ of playoff participations are predicted correctly, ${ }^{14}$ while the adjusted count $R^{2}$ equals 0.7. Furthermore, unreported results show that the model's predictions become more accurate as the season progresses.

Finally, we measure the importance of a given game by the estimated difference between the probability of the team reaching the playoffs if it wins the game and the probability of the team reaching the playoffs if it loses the game. Formally, we estimate game importance as follows:

Game Importance

$$
=\operatorname{Prob}(\text { playoffs }=1 \mid \text { team wins })-\operatorname{Prob}(\text { playoffs }=1 \mid \text { team losses })
$$

A larger difference between the two predicted probabilities indicates that the individual game matters more. Figure 1 provides a graphic illustration of our game importance measure for two seasons of the Chicago Bulls, 2009-2010 (Figure 1.1) and 2010-2011 (Figure 1.2). The dots in each graph represent the Bulls’ ranking in the Eastern Conference prior to each individual

\footnotetext{
${ }^{13}$ Recall that eight teams from each conference make the playoffs. Thus, the larger the gap between the wins of a given team and the wins of the eighth team in its conference, the more likely it is that the given team will reach the playoffs at the end of the season (and vice versa if the gap is smaller).

${ }^{14}$ In the count $R^{2}$ measure, if a predicted probability is above 0.5 , it is regarded as a prediction that the team will reach the playoffs, while if it is smaller than 0.5 , it is regarded as a prediction that the team will not reach the playoffs.
} 
game. The line in each graph represents the importance of the next individual game as reflected in our game importance measure.

As Figure 1.1 shows, the Bulls' conference rank during the 2009-2010 season was quite volatile, with the team bubbling around the eighth spot throughout the regular season. Figure 1.1 shows how game importance peaked toward the end of the season when it was unclear whether the Bulls would finish eighth (reaching the playoffs) or ninth (being excluded from the playoffs) in the Eastern Conference. By contrast, during the 2010-2011 season, the Bulls performed very well. Figure 1.2 shows that, after fewer than twenty games, game importance for the Bulls dropped substantially as it became clear that they would make it to the playoffs.

\section{Coach Termination Risk and Rookie Playing Time}

\section{A. The Expected Role of Termination Risk}

Decisions concerning whether and when to use a given player in a game are typically made by the team's head coach. While the coach reports to and may be fired by the team's owner, the owner (and the general manager who works on the owner's behalf) has good reasons to provide the coach with substantial discretion with respect to such decisions. To begin with, the optimal use of rookies might well depend on factors about which the coach is better informed than the owner (and general manager), such as the rookie's performance in practice and the situation of the game when the decision has to be made. If the owner or general manager were to intervene and give the coach instructions regarding rookie participation either before or during the game, some of the benefits of the superior information available to the coach would be forgone.

Furthermore, giving such instructions might be costly in terms of undermining the authority of the coach and/or reducing his effort and motivation (Change and Lai (1999), Dickinson and Villeval (2008) and Frey(1993)). Consequently, owners (and their general managers working on their behalf) can be expected to refrain from intervening in coaches' decisions regarding rookie participation absent a strong reason to do so.

While letting a rookie participate in a given game has short-term implications for the outcome of the game and the team's overall record for the current season, doing so may produce at least two kinds of long-term payoffs beyond the current season. First, it can contribute to developing the rookie's skills and thus can be viewed as an investment in the rookie's human 
capital, which can benefit the team during subsequent years under the rookie's contract. $^{15}$ Second, it can provide valuable input for the team owners down the road when they will need to decide whether to retain or trade the rookie.

The long-term benefits that playing rookies in a given year can be expected to generate for the team can accrue to team owners as well. Team owners care about the success of their teams because such success provides them with monetary benefits and might also carry enhanced prestige or status. To be sure, there may be owners who attach little value to the long-term benefits of playing rookies because they are planning to sell their teams soon. However, during the ten-year period that we investigate, owner turnover was infrequent (only ten cases), and owners owned their teams for an average of twenty two years.

From the perspective of the team and its owner, the optimal decision regarding the participation of a given rookie should depend only on the characteristics of the rookie, the team, and the game. It should not depend on the risk of termination that the coach faces. However, a high risk of termination might introduce agency distortions, leading the coach to place less weight on long-term consequences. A coach with a high risk of termination has an incentive to underuse rookies if doing so will improve short-term results and thereby increase his odds of retaining his current job or landing an alternative job in case he is fired. ${ }^{16}$

Because agents who face a high risk of termination in the short term might engage in "shorttermism” and underinvest in projects whose payoffs would be realized only in the long term, an association between coach termination risk and lower rookie participation may result. We therefore tested the hypothesis that, other things being equal, coaches with a high risk of termination can be expected to be associated with lower rookie participation.

As shown on Table 1, the mean season-level PER of rookies is 11.7, compared to 12.6 for all veteran players, with the difference being significant at the $1 \%$ level. This difference might indicate that, in the aggregate, NBA coaches do give some weight to the long-term benefits of

\footnotetext{
${ }^{15}$ Much of this benefit can be expected to be captured by the rookie himself, who will be free to leave after his contract ends. However, since the CBA gives the current team an advantage in keeping its rookie players, the team might be able to capture at least some of the benefits that accrue from the fifth year and on.

${ }^{16}$ As Stein (1988) shows, while in equilibrium outsiders may anticipate this type of distortion, as long as outsiders do not directly observe the optimal choice for any given rookie participation decision, coaches with short investment horizons will have a private incentive to underinvest in rookies.
} 
playing rookies and let rookies play more than would be optimal if they focused exclusively on short-term results. However, our hypothesis is that a high risk of termination leads coaches to make different decisions in circumstances that are otherwise similar.

\section{B. The Relationship of Coach Termination Risk and Rookie Participation}

To test our hypothesis, we began by focusing on decisions that were made under the 1999 CBA, in which teams were given the option to decide at the end of a player's second year whether to extend his rookie contract for a fourth year (beyond the three guaranteed years). We expected that, under the 1999 CBA, coaches with a high risk of termination-and thus a short investment horizon-were less willing to let rookies play than were coaches with a low risk of termination, assigning a relatively higher weight to the short-term objective (winning games) and a relatively lower weight to the long-term objective (developing rookies) than did coaches with a lower termination risk. ${ }^{17}$ We, therefore, run the following linear probability model:

$$
\text { Played }_{p, c, t, s, g}=\text { Termination_risk }_{c, s, g} \tau+X_{p}^{\prime} \gamma+Z_{p, c, t, s, g}^{\prime} \theta^{\prime}+\delta_{t}+\gamma_{c}+\varepsilon_{p, c, t, s, g}
$$

In the above specification, $p$ indicates the player, $c$ the coach, $t$ the team, $s$ the season, and $g$ the specific game. Our dependent variable, Played $_{p, c, t, s, g}$, is a dummy variable that equals 1 if player $p$ from team $t$ with coach $c$ participated in game $g$ during season $s$, and equals 0 otherwise. Our main explanatory variable of interest is the termination risk of the coach at the beginning of the current game. This variable is one that we estimated in Section IV.A.

It is worth noting that some coaches may well have had private information with respect to their probability of being fired or not. To the extent that they did, our estimated risk termination is noisy proxy for the actual termination risk known to coaches and influencing their decisions. In such a case, our error in estimating the actual termination risk could introduce measurement errors that could work against our finding statistical significance.

The vector $X_{p}$ includes control variables on the player's general characteristics-those that do not change over time. This vector includes the rookie's draft rank, the rookie's position (center, forward, or guard); a dummy variable indicating whether the rookie is a foreigner; a

\footnotetext{
${ }^{17}$ We focus on coaches who were fired, because firing appears to have significant adverse effects on such coaches and, in any event, termination accounts for the lion's share of coach departures in our sample. In unreported tables, we redid our analysis focusing on the odds of departure for any reason other than termination and achieved similar results
} 
dummy variable indicating whether the rookie skipped college and, if not, the number of years he spent in college; and a dummy variable indicating whether the rookie was traded.

The vector $Z_{p, c, t, s, g}$ includes characteristics that vary over time: the team's win-loss record going into the current game; the strength of the opposing team (as measured by its record at the time of the game); the number of games played so far in the season; a dummy variable indicating whether the opponent is from the same conference; a dummy variable indicating whether this is a home game for the rookie's team; and the team's ranking at the end of the preceding season. The vector also contains a control variable for the rookie's performance relative to that of other players on his team (the difference in the moving averages between the rookie's game-level PER and the game-level PER of his teammates prior to the current game), and a control variable for the accumulated number of minutes that the rookie played prior to the current game.

Finally, we include fixed effects: $\delta_{t}$ indicates team-fixed effects, and $\varphi_{c}$ indicates coachfixed effects. ${ }^{18}$ Our standard errors are clustered by player identification number. While we used team-fixed effects at this stage, we confirm later that our results hold when owner- and general manager-fixed effects are added.

Table 5 presents the results of the above regression. Column (1) indicates that coaches who face a higher termination risk tend to play rookies less frequently. In this specification, the coefficient of Termination Risk is -0.321 and is statistically significant at the $1 \%$ level. The coefficient suggests that, holding other things equal, a 10 percentage point increase in the probability that the rookie's coach will be fired is associated with a 3.2 percentage point reduction in the probability that the rookie will play in the current game. Considering that the range of coach termination risk in our sample is between $0 \%$ and $99 \%$ (with a mean of $21 \%$ and standard deviation of $41 \%$ ), a 10 percentage point increase in coach termination risk is within the range of potential changes in termination risk.

Because our main variable of interest, Termination Risk, is based on an estimate produced by a separate regression, we need to adjust our standard errors to avoid standard errors that would be biased downward. We therefore use bootstrapping (as suggested by Petrin and Train

\footnotetext{
${ }^{18}$ We also present robustness tests with various different fixed effects.
} 
$2003)^{19}$ to add the additional source of variance to the estimated variance of the parameters of our regressions.

Using bootstrapped samples, we repeatedly predict termination risk 100 times for each coach's game. We then estimate our linear probability model from Column (1) 100 times, where the only variation between one run and the other is in the value of the predictions of termination risk, which we obtain from the different bootstrap samples. We then add the variance in the parameter estimates obtained from these 100 estimations to the variance estimates obtain from the original model presented in Column (1) (which assumes that the measures are the true ones).

Column (2) of Table 5 presents the results of the same regression, corrected for the standard errors using the bootstrap procedure described above. While the standard errors increase somewhat, the qualitative results do not change, with the coefficient of Termination Risk remaining statistically significant at the $1 \%$ level. Thus, the results are consistent with a correlation between coach termination risk and lower rookie participation.

It might be argued that the identified association might be driven by some mechanism other than the agency problems of short-termism introduced by termination risk and the resulting short horizon. To begin with, it might be suggested that some coaches (because of their personality, basketball philosophy, or other personal traits) simply have a tendency not to play rookies and that such coaches also tend to be unsuccessful and to face higher termination risk. However, our specifications use coach-fixed effect and thus cannot be fully explained by differences in personal traits and attitudes among coaches.

It might also be speculated that coaches whose teams have weak rookies can be expected both to let rookies play less often and to be less successful because of the weak rookies they have. However, our specifications control for the quality/rank of the rookie. Moreover, given the NBA's procedure of allocating high-ranked draft picks to teams with weak records in the preceding season, coaches of such teams tend to have higher-quality rookies. Thus, to the extent that our controls fail to control precisely for rookie quality, this failure can be expected to work in the opposite direction and thus, if anything, bias the correlation we estimate downward.

In assessing whether the identified association could be driven by a mechanism other than the agency problems introduced by high termination risk, it is worth noting that one of the variables

\footnotetext{
${ }^{19}$ Karaca-Mandic and Train (2003) show that the standard errors obtained using bootstrap methods are similar to those obtained from using asymptotic formulae.
} 
we use to determine risk termination appears to be exogenous and thus unlikely to be correlated directly with lower rookie participation. In particular, as discussed in the preceding section, this appears to be the case with respect to the number of years left on the coach's contract.

Finally, in assessing whether the identified association could be fully driven by some other mechanism, we should take into account not just the identified association but also three other findings that we document below. That is, for our findings as a whole to be driven by some other mechanism, that mechanism would have to explain not only the identified association under the 1995 CBA but also why the identified association (i) was driven by important games, (ii) disappeared after the introduction of the 2005 CBA, and (iii) did not exist for second-year players. Each of these three findings, which we document below, is consistent with the shorttermism agency mechanism.

\section{The Role of Game Importance}

When a game is important and the costs of losing it are great, a coach who overvalues shortterm results is especially likely to avoid letting rookies play. We therefore hypothesize that the association between high termination risk and low rookie participation is especially strong in, and even driven by, important games.

We use two specifications to test this hypothesis. The first includes only our measure of game importance:

$$
\text { Played }_{p, c, t, s, g}=\text { Game_Importance }_{s, g} \rho+X_{p}^{\prime} \gamma+Z_{p, c, t, s, g}^{\prime} \theta+\delta_{t}+\gamma_{c}+\varepsilon_{p, c, t, s, g}
$$

The second also includes the variable Termination Risk and its interaction with Game Importance:

$$
\begin{aligned}
& \text { Played }_{p, c, t, s, g}=\text { Termination }_{\text {Risk }_{c, s, g}} \tau+\text { Game Importance }_{t, s, g} \rho+ \\
& \text { Termination_Risk }{ }_{c, s, g} \times \text { Game Importance }{ }_{t, s, g} \pi++Z_{p, c, t, s, g}^{\prime} \theta \\
& +X_{p}^{\prime} \gamma+\delta_{t}+\gamma_{c}+\varepsilon_{p, c, t, s, g}
\end{aligned}
$$

As before, the main regressors are estimates coming from different regressions, and so we adjust the standard errors using a bootstrap procedure similar to the one described earlier. ${ }^{20}$ Table 6, Columns (1) and (3), display the results for the two specifications when the bootstrap procedure was not used, and Columns (2) and (4) display the results when it is used.

\footnotetext{
${ }^{20}$ We bootstrapped these three variables 100 times, estimating each specification 100 times and adding the additional source of variation to the estimated variances of the reported coefficients.
} 
In Columns (1) and (2), when we use Game Importance without Termination Risk, the coefficient of Game Importance is negative but not statistically significant. Thus, across all coaches, both those with high and those with low termination risk, there is no statistically significant correlation between game importance and rookie participation. However, in Columns (3) and (4), the interaction term between Game Importance and Termination Risk is equal to -3.065 and is statistically significant at the $5 \%$ level. Thus, the data are consistent with coaches who have high termination risk-but not with those who have low termination risk-using rookies less often in important games.

We now turn to see whether this effect, in addition to being statistically significant, is also economically significant. The mean Game Importance level in our sample equals 0.045, indicating that the mean effect of winning a game on playoff participation is $4.5 \%$. Therefore, at the mean Game Importance, the overall effect of a 10 percentage point increase in probability that the coach will be fired is associated with a 2.7 percentage point reduction in probability that the rookie will play. The coefficients of the other control variables that are statistically significant mostly have the expected signs.

Finally, Table 7 shows that our results are robust to different choices of fixed effects. Column (1) shows that the results obtained in Table 6, Column (4), are robust to using team- and coach-fixed effects. Column (2) replaces the team- and coach-fixed effects with team- and season-fixed effects. Column (3) uses team-, coach-, and season-fixed effects, and Column (4) uses player-fixed effects. All specifications in Table 7 include the same control variables as in Table 6, and the standard errors are corrected using the bootstrap procedure used earlier. Both the magnitude and the significance of the results in Table 7 are similar to those reported in Table 6 .

\section{Different Settings and Robustness}

\section{A. The Effect of the 2005 CBA}

Our earlier discussion of coaches' decisions was based on the assumption that, during the period governed by the 1999 CBA, team owners largely left rookie participation decisions to the discretion of coaches. This discretion, coupled with the short-term focus of some coaches, could have led to the pattern identified in the preceding section. However, we conjecture that there 
could be circumstances that lead owners to reduce the discretion they leave to coaches with respect to rookie participation decisions.

Recall that while the coach makes tactical participation decisions during games, team owners (and the general managers working for them) commonly take the lead in general personnel decisions, including drafting rookies; signing free agents; and retaining, releasing, and trading players. Therefore, we conjecture that, in the year leading to a contract extension decision for a given player, a team owner has a strong interest in ensuring that the player participates in games and thus provides the basis for an informed extension decision. In such a situation, team owners (and their general managers) might thus have a greater incentive (1) to invest more in monitoring rookie participation decisions as well as (2) to overcome any reluctance to intervene in tactical game decisions and press coaches regarding the rookie participation issue.

Our dataset provides a "natural experiment" that enables us to test this conjecture. Whereas the 1999 CBA provided teams with the option of deciding at the end of the second year whether to extend the three years' guaranteed contract by one year or to shorten it by one year (by "waiving” the fourth year), the 2005 CBA shortened the guaranteed contract to two years and added an option to decide at the end of the first year whether to shorten the contract by two years (by waiving both the third and fourth years). This contractual change increased the incentive of team owners to obtain information about rookies’ performances and thus to ensure that rookies get to play. We thus hypothesize that the introduction of the 2005 CBA would weaken or eliminate the association between termination risk and lower rookie participation that existed under the $1999 \mathrm{CBA}^{21}$

Column (1) of Table 9 provides the results for the 2005 CBA of the linear probability model of our main specification (Table 6, Column (4)). Consistent with our hypotheses, the coefficient of the interaction terms of Termination Risk and Game Importance is now, unlike in Table 6, close to 0 and statistically insignificant. Thus, our results are consistent with the hypothesis that

\footnotetext{
${ }^{21}$ An additional reason why short-termism might be less pronounced under the CBA 2005 is that the contractual change also provided rookies with incentives to exert more effort in the first year since that year became a contract extension year. Consequently, the gap in performance between rookies and veterans may have diminished, reducing the short-term cost of playing rookies. Relatedly, Stiroh (2007) shows that NBA players (both veterans and rookies) perform significantly better before signing a multiyear contract.
} 
the introduction of the 2005 CBA weakened or eliminated the association between termination risk and lower rookie participation in important games.

\section{B. Second-Year Players}

We conjecture that, under both the 1999 and the 2005 CBAs, the association between coach termination risk and player participation was weaker, if not nonexistent, with respect to players in their second year with the NBA. To begin, because second-year players already have a year of NBA experience, both the short-term costs of letting them play and the long-term benefits of providing them with additional experience are smaller. Thus, any undervaluation of long-term effects should not be expected to influence participation decisions for second-year players as much as for rookies. In addition, under both CBAs, teams could decide at the end of the second year whether to waive the option to keep the player for the fourth year. Therefore, as argued above, team owners could be expected to take an interest in ensuring that second-year players get opportunities to participate that could inform the decision about whether to exercise the waiver option.

We test the above conjecture by rerunning our main specification. We expect the identified differences between coaches with higher and lower termination risk regarding rookie participation to diminish or disappear with regard to the participation of second-year players.

Column (2) of Table 9 reruns our main specification (Table 6, Column (4)) for second-year players during the 1999 CBA, and Column (3) of Table 9 does so for second-year players during the 2005 CBA. Consistent with our conjecture, the interaction term of Termination Risk and Game Importance is no longer significant in either column. Thus, the evidence is consistent with the hypothesis that the identified association between coach termination risk and lower rookie participation in important games did not exist for second-year players.

\section{Robustness Tests}

\section{Diff-in-Diff-in-Diff Specification}

For robustness tests, we run a Diff-in-Diff-in-Diff (DDD) specification. We run it once for rookies (under both CBAs) and once for second-year players (under both CBAs). For the DDD specification, we add another dummy variable, CBA_05, which equals 0 for the 1999 CBA and 1 
for the 2005 CBA. We also interacted the CBA_05 dummy variable with each of our three variables of interest: Termination Risk, Game Importance, and their interaction term.

Column (1) of Table 10 shows that, using the above specification, the interaction term between Termination Risk and Game Importance is negative and statistically significant at the $1 \%$ level. This result is consistent with our earlier finding of a negative association between termination risk and participation in important games under the 1999 CBA. Furthermore, the triple interaction between Termination Risk, Game Importance, and CBA_05 in Column (1) of Table 10 is positive and significant at the $1 \%$ level. This result is consistent with our earlier finding that the introduction of the 2005 CBA weakened the association between coach termination risk and lower rookie participation in important games.

Column (2) of Table 10 provides the results for second-year players. Both the interaction term between Termination Risk and Game Importance and the triple interaction with the CBA_05 dummy are close to 0 and insignificant. This result is consistent with our earlier finding that the

identified association between coach termination risk and lower participation was limited to rookies and did not exist for second-year players.

\section{Owner- and General Manager-Fixed Effects}

We also test whether our results are robust to the introduction of owner- and general manager-fixed effects. Therefore, to allow for the possibility that the rookie participation decisions of coaches are influence by the heterogeneity of NBA team owners, we introduce team owner- and team general manager-fixed effects.

To this end, we collected data from various online resources concerning the identity of team owners for each season, and for each team in a given season we computed the number of years that the owner was with the team. During our period of study, there were forty different owners, and owners owned their team for a period of twenty-two years on average. In addition, we obtained data from Basketball-Reference.com concerning the identity of each team's general manager during each season and computed the general manager's tenure with the team. Our sample includes seventy-three individual general managers, with tenures ranging from zero to twenty-two years and averaging five years.

In untabulated regressions, we reestimate our main linear probability model (Table 6, Column (4)), adding owner-fixed effects, the owner's length of ownership, general 
manager-fixed effects, and the length of the general manager's service with the team. ${ }^{22}$ The model is estimated four times, once for each of our main subsamples: rookies under the 1999 CBA, rookies under the 2005 CBA, second-year players under the 1999 CBA, and second-year players under the 2005 CBA.

The results of these untabulated regressions indicate that, as we found earlier, the coefficient of the interaction between Termination Risk and Game Importance is negative and significant only for rookies under the 1999 CBA but not for any of the other three subsamples, and that the magnitude of the estimated effect is practically identical to that reported in Table 6, Column (4). Thus, our results are robust to the inclusion of owner-fixed effects, general manager-fixed effects, and controls for the length of time that the owner and the general manager have been with the team.

\section{Conclusion}

This paper has studied empirically the agency problems produced when agents have high termination risks and short investment horizons. We have studied this issue in the context of the decisions of NBA coaches whether to let rookies play. We find that, during the period of the NBA's 1999 CBA, coaches with a high risk of termination by the end of the season allowed rookies to participate less frequently. The identified association was driven by important games. We have also found that the identified association did not exist for second-year players, for whom providing NBA experience was not as critical, and that the association ceased to exist for rookies after the 2005 CBA increased owners' incentive to ensure that rookies get opportunities to play. Our analysis highlights the value of studying short-termism agency problems among agents other than CEOs of business firms.

\footnotetext{
${ }^{22}$ The model still includes all the controls used in Table 6, column (4). Team-fixed effects were excluded because of their multicolinearity with owner fixed effects.
} 


\section{References}

Abramitzky, Ran, Liran Einav, Shimon Kolkowitz, and Roy Mill (2012), “On the Optimality of Line Call Challenges in Professional Tennis,” International Economic Review, Vol. 53, No. 3, pp: 939-964.

Aghion, Philippe, John Van Reenen, and Luigi Zingales, (2010), “Innovation and institutional ownership,” American Economic Review, Vol. 103, No. 1, pp. 277-304.

Asker, John William, Joan Farre-Mensa and Alexander Ljungqvist, (2014), “Corporate Investment and Stock Market Listing: A Puzzle?," Working Paper, available at http://dx.doi.org/10.2139/ssrn.1603484

Azoulay, Pierre, Gustavo Manso and Joshua Graff Zivin (2011), “Incentives and Creativity: Evidence from the Academic Life Sciences. RAND Journal of Economics,” Vol. 42, No. 3, pp. 527-554.

Banaian, King; Gallagher, Dan (1999), "When a Cap is not a Cap: Player Mobility and Pay in the NBA,” mimeo.

Bebchuk, Lucian and Lars Stole, "Do Short-Term Managerial Objectives Lead to Under- or Over-Investment in Long-Term Projects?,” Journal of Finance, Vol. 48, pp. 719-729.

Bernstein, Shai (2012), “Does Going Public Affect Innovation?,” Working Paper, available at SSRN: http://dx.doi.org/10.2139/ssrn.2061441

Bolton, Patrick, Jose Scheinkman and Wei Xiong (2006), "Executive Compensation and Shorttermist Behavior in Speculative Markets,” Review of Economic Studies, Vol. 73, pp: 577-610.

Camerer, Colin F., and Roberto A. Weber, (1999), “The Econometrics and Behavioral Economics of Escalation of Commitment: A Re-Examination of Staw and Hoang's NBA Data,” Journal of Economic Behavior \& Organization, Vol. 39, No. 1, pp. 59-82.

Chang J. and Lai, C. (1999), “Carrots or Sticks? A Social Custom Viewpoint on Worker Effort,” European Journal of Political Economy, Vol. 15, pp. 297-310.

Chiappori, Pierre-André; Levitt, Steven; and Groseclose, Timothy. “Testing Mixed-Strategy Equilibria When Players Are Heterogeneous: The Case of Penalty Kicks in Soccer.” American Economic Review, September 2002, Vol. 92, No. 4, pp. 1138-51. 
Dechow, P. and R. Sloan (1991) "Executive incentives and the horizon problem: An empirical investigation,” Journal of Accounting and Economics, Vol14, Issue 1, pp. 51-89.

Dickinson, D. and Villeval M. (2008), “Does Monitoring decrease Work Effort? The complementarity between agency and crowding-out Theories," Games and Economic Behavior, Vol. 63(1), pp. 56-76

Duggan, Mark and Steven D. Levitt (2002), "Winning is not Everything: Corruption in Sumo Wrestling," American Economics Review, Vol. 92, No. 2, pp: 1594-1605.

Edmans, Alex, Vivian W. Fang and Katharina A. Lewellen (2013), “Equity vesting and managerial myopia,” Working Paper, London Business School.

Frey, B.S (1993), "Does monitoring increase work effort? The rivalry with trust and loyalty,” Economic Inquiry, Vol. 31, pp. 663-670

Garicano, Luis, Ignacio Palacios-Huerta, and Canice Prendergast (2005), "Favoritism Under Social Pressure,” The Review of Economics and Statistics, Vol. 87, No. 2, pp: 208-216

Gonzalez, Angelica and Paul André (2012), “Board Effectiveness and Short-Termism,” Working Paper, available at SSRN: http://ssrn.com/abstract $=1979751$

Groothuis, Peter A., James Richard Hill, and Timothy J. Perri (2007), "Early Entry in the NBA Draft. The Influence of Unraveling, Human Capital, and Option Value,” Journal of Sports Economics, Vol. 8, No. 3, pp. 223-243.

Hausman, Jerry A. and Gregory K. Leonard (1997), "Superstars in the National Basketball Association: Economic Value and Policy.” Journal of Labor Economics, Vol. 15, No. 4, pp. 586-624.

Hollinger, John. Pro Basketball Forecast, 2005-06. Potomac Books, 2005.

Holmstrom, Bengt (1999), "Managerial Incentive Problems: A Dynamic Perspective," The Review of Economic Studies, Vol. 66, No. 1, pp: 169-182

Kahane, Leo, Neil Longley, and Robert Simmons (2013), “The Effect of Coworker Heterogeneity on Firm-Level Output: Assessing the Impacts of Cultural and Language Diversity in the National Hockey League,” The Review of Economics and Statistics, Vol. 95, No.1, pp: 302-314. 
Kahn, M. Lawrence (2000), “The Sport business and a Labor Market Laboratory,” Journal of Economics Perspective, Vol. 14, No. 3, pp: 75-94.

Karaca-Mandic, Pinar, and Kenneth Train (2003), "Standard error correction in two-stage estimation with nested samples,” The Econometrics Journal, Vol. 6, No. 2, pp: 401-407.

Ladika, Tomislav and Zacharias Sautner (2013), “The Effect of Managerial Short-Termism on Corporate Investment,” Working paper available at http://papers.ssrn.com/sol3/papers.cfm?abstract_id=2286789

Narayanan, M.P (1985), “Managerial Incentives for Short-term Results,” Journal of Finance, Vol. 40, No. 5, pp: 1469-1484.

Nikhil, Joshi (2011), “The Market for Talent: Are Top Draft Picks Overpaid?”, mimeo.

Parson, Christopher A. Sulaeman, Johan, Yates, Michael C, and Hamermesh, Daniel S. (2011), "Strike Three: Discrimination, Incentives, and Evaluation,” The American Economic Review, Vol. 101, No. 4, pp. 1410-1435.

Petrin, Amil, and Kenneth Train (2003), “Omitted product attributes in discrete choice models,” National Bureau of Economic Research Working Paper, w9452.

Price Joseph and Justin Wolfers (2010), “Racial Discrimination among NBA Referees,” The Quarterly Journal of Economics, Vol. 125, No. 4, pp: 1859-1887

Romer, David. “Do Firms Maximize? Evidence from Professional Football.” Journal of Political Economy, April 2006, Vol. 114, No. 2, pp. 340-65.

Staw, Barry M., and Ha Hoang (1995), "Sunk costs in the NBA: Why draft order affects playing time and survival in professional basketball,” Administrative Science Quarterly, Vol. 40, No. 3, pp: 474-494.

Stein, Jeremy (1988), “Takeover Threats and Managerial Myopia,” Journal of Political Economy, Vol. 96, no. 1, pp: 61-80.

Stein, Jeremy (1989), "Efficient Capital Markets, Inefficient Firms: A Model of Myopic Corporate Behavior,” Quarterly Journal of Economics, Vol. 104, pp: 655-669.

Stiroh, Kevin J. (2007) "Playing for Keeps: Pay and Performance in the NBA,” Economic Inquiry, Vol. 45, No. 1, pp: 145-161. 
Von Thadden, Ernst-Ludwig, (1995) “Long-term contracts, short-term investment, and monitoring,” Review of Economic Studies, Vol. 62, pp: 557-575.

Xu, Moqi, (2013), “The costs and benefits of long-term CEO contracts,” working paper, London School of Economics. 
Figure 1: Game Importance Measure

Figure 1: Illustrating Game Importance

Fig. 1.1: Chicago Bulls, 2009-2010 season Finished 8th, Eastern Conference

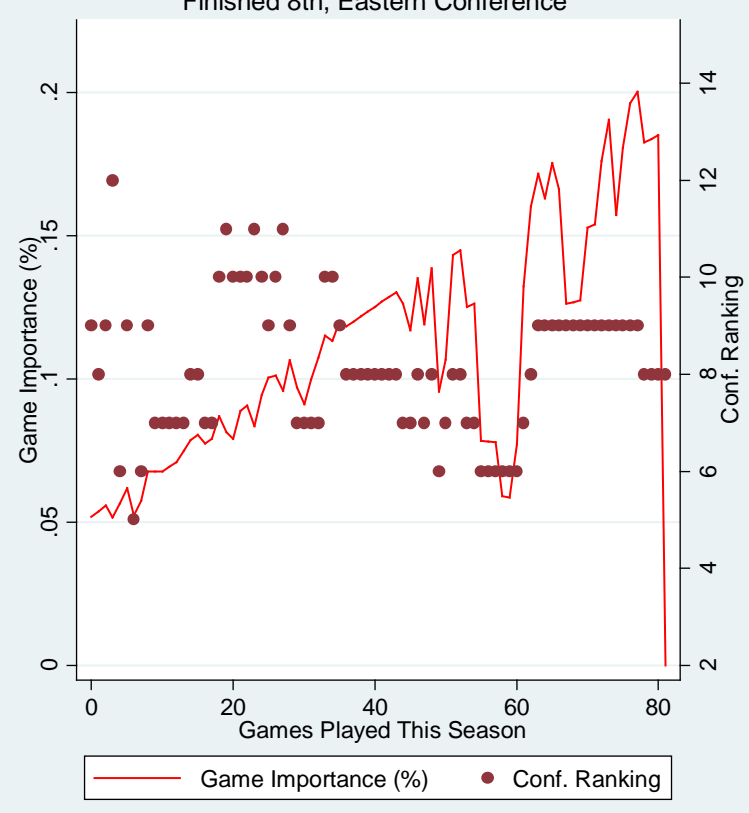

Fig. 1.2: Chicago Bulls, 2010-2011 season Finished 1st, Eastern Conference

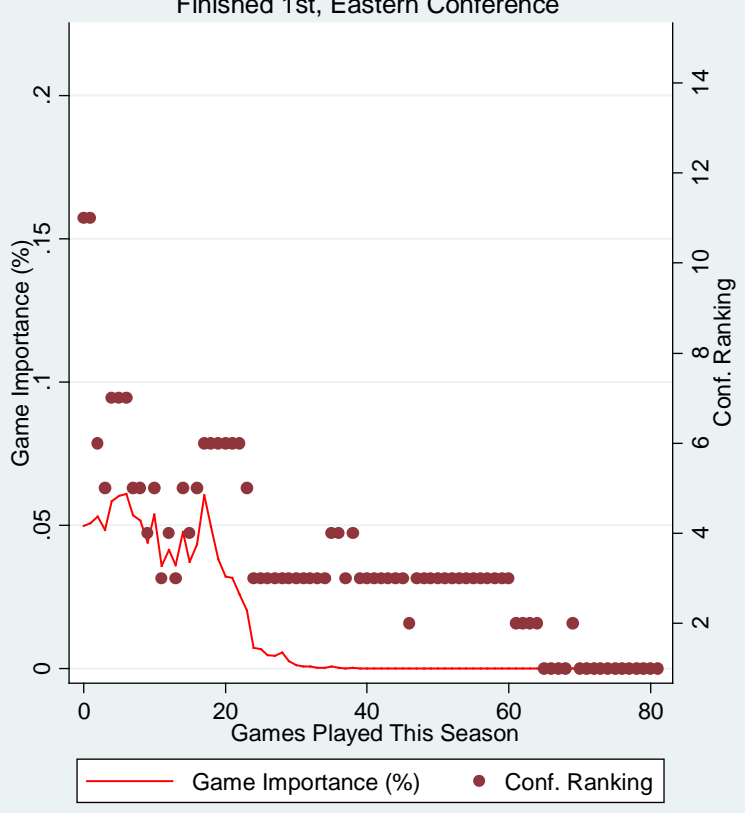


Table 1: Summary Statistics: Player-Game-Level Data

\begin{tabular}{lccccc}
\hline & & 1999 CBA & 2005 CBA & & \\
& $(1)$ & $(2)$ & $(3)$ & $(4)$ & $(5)$ \\
& Total & Rookies & Second Year & Rookies & Second Year \\
\hline Played & 0.73 & 0.67 & 0.75 & 0.75 & 0.75 \\
& $(0.44)$ & $(0.47)$ & $(0.43)$ & $(0.43)$ & $(0.43)$ \\
Draft Rank & 14.94 & 14.75 & 14.42 & 15.48 & 15.21 \\
Center & $(8.37)$ & $(8.36)$ & $(8.30)$ & $(8.45)$ & $(8.33)$ \\
& 0.15 & 0.17 & 0.16 & 0.12 & 0.12 \\
Forward & $(0.35)$ & $(0.38)$ & $(0.37)$ & $(0.33)$ & $(0.33)$ \\
& 0.45 & 0.44 & 0.45 & 0.47 & 0.45 \\
Foreigner & $(0.50)$ & $(0.50)$ & $(0.50)$ & $(0.50)$ & $(0.50)$ \\
& 0.15 & 0.17 & 0.16 & 0.13 & 0.12 \\
Skipped College & $(0.35)$ & $(0.38)$ & $(0.36)$ & $(0.33)$ & $(0.33)$ \\
& 0.08 & 0.12 & 0.13 & 0.03 & 0.03 \\
College Years & $(0.27)$ & $(0.33)$ & $(0.34)$ & $(0.17)$ & $(0.17)$ \\
& 2.1 & 1.96 & 2 & 2.26 & 2.23 \\
Traded & $(1.51)$ & $(1.57)$ & $(1.58)$ & $(1.41)$ & $(1.40)$ \\
& 0.02 & 0.01 & 0.01 & 0.01 & 0.05 \\
Balance & $(0.14)$ & $(0.10)$ & $(0.11)$ & $(0.10)$ & $(0.22)$ \\
& -2.87 & -2.59 & -1.43 & -4.05 & -3.62 \\
Opponent Balance & $(14.25)$ & $(14.35)$ & $(13.93)$ & $(14.62)$ & $(13.95)$ \\
& 0.04 & -0.05 & -0.01 & 0.16 & 0.07 \\
Games Played & $(14.26)$ & $(13.92)$ & $(13.50)$ & $(14.85)$ & $(14.89)$ \\
& 41.34 & 41.76 & 41.24 & 41.7 & 40.53 \\
Same Conference & $(23.69)$ & $(23.73)$ & $(23.69)$ & $(23.68)$ & $(23.65)$ \\
& 0.33 & 0.36 & 0.34 & 0.31 & 0.31 \\
Home Team & $(0.47)$ & $(0.48)$ & $(0.47)$ & $(0.46)$ & $(0.46)$ \\
PER & 0.5 & 0.5 & 0.5 & 0.5 & 0.5 \\
Minutes & $(0.50)$ & $(0.50)$ & $(0.50)$ & $(0.50)$ & $(0.50)$ \\
$\mathrm{N}$ & 11.7 & 10.87 & 12.42 & 11.02 & 12.53 \\
& $(13.20)$ & $(13.67)$ & $(12.92)$ & $(13.50)$ & $(12.57)$ \\
& 16.18 & 13.66 & 17.84 & 15.12 & 18.49 \\
& $(14.18)$ & $(13.80)$ & $(14.61)$ & $(13.23)$ & $(14.51)$ \\
\hline & 48,191 & 13,327 & 12,614 & 11,515 & 10,735 \\
\hline
\end{tabular}

Notes: The sample includes game-level information for all first round rookies drafted from 1999 to 2010. The sample includes information concerning the rookies' first and second year at the NBA. Means are reported for the entire sample and also broken down by CBA and year of the rookie (standard deviations are reported in parentheses). Played is a dummy variable indicating whether the rookie played in a specific game; Draft Rank is the rookie's draft ranking (the first drafted rookie is assigned the value 1); Center and Forward indicate the rookie's position; Foreigner indicates the rookie was born and attended high-school outside the USA; Skipped College indicates the rookie was born in the USA and did not attend college; College Years indicates number of years attended college; Traded indicates the rookie was traded in the middle of the season; Balance is a calculation of wins minus losses of the rookie's team, prior to the current game; Opponent Balance similar, only for the opposing team; Games Played indicates the number of games the team has played so far in the season; Same Conference indicates the opposing team is from the same conference; Home Team indicates the rookie's team is the home team during the current game; PER is John Hollinger's Player Efficiency Rating (computed at the game level); Minutes is the number of minutes played in current game. 
Table 2: Summary Statistics - Coach-Season-Game Level Data

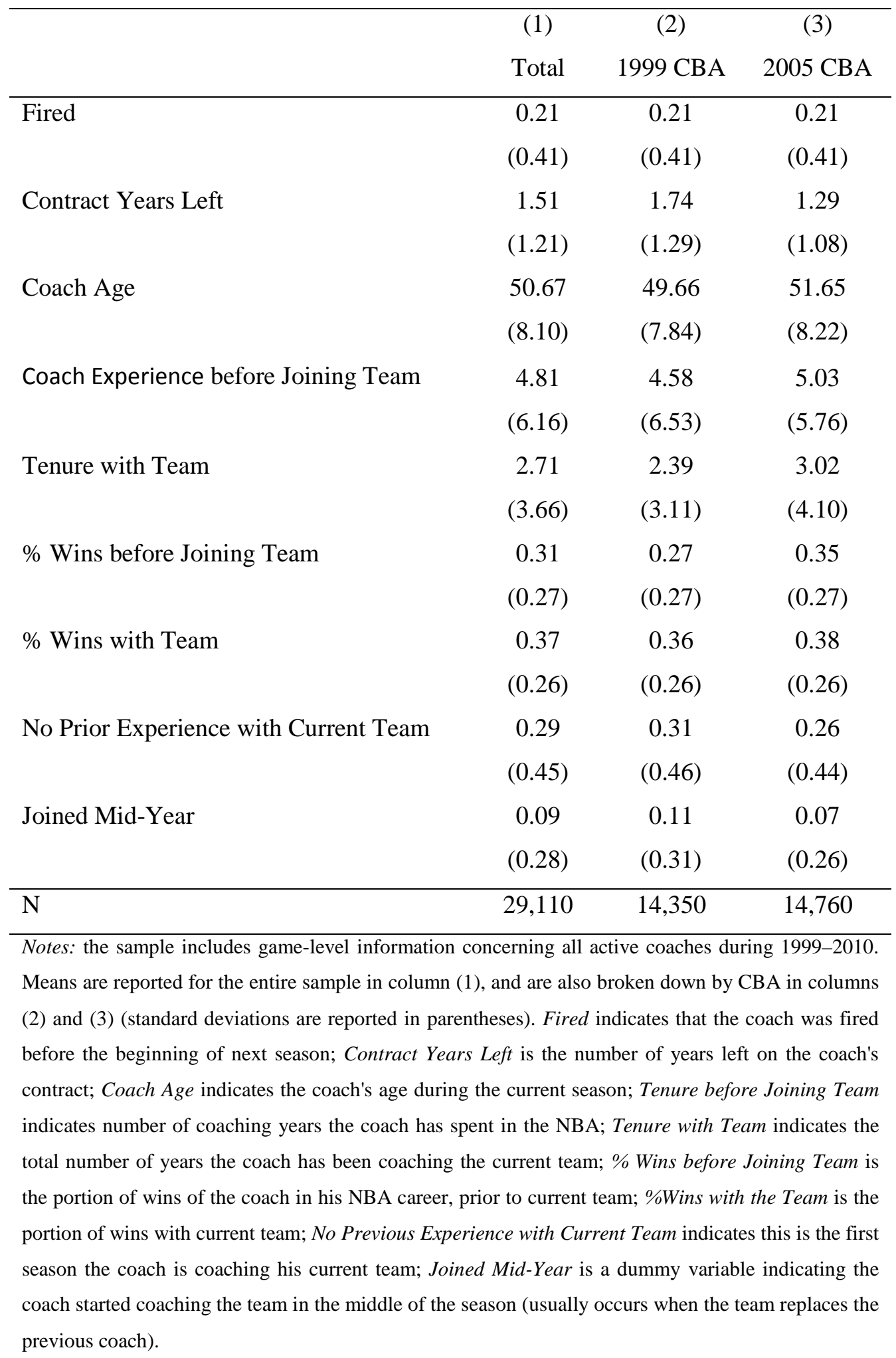


Table 3: Coach Termination Risk - Probit Regression Results, Team Fixed Effects (Dependent Variable - Coach Terminated by End of Season)

\begin{tabular}{|c|c|}
\hline Covariates & $\begin{array}{c}\text { (1) } \\
\text { Coach Terminated }\end{array}$ \\
\hline Contract Years left & $\begin{array}{c}-0.580^{* * *} \\
(0.11)\end{array}$ \\
\hline Coach Age & $\begin{array}{l}0.239 \\
(0.18)\end{array}$ \\
\hline Coach Age $^{2}$ & $\begin{array}{c}-0.00214 \\
(0.00)\end{array}$ \\
\hline East Conference & $\begin{array}{l}0.879^{*} \\
(0.35)\end{array}$ \\
\hline Coach Experience before Joining Team & $\begin{array}{c}-0.160^{*} \\
(0.07)\end{array}$ \\
\hline (Coach Experience before Joining Team) $^{2}$ & $\begin{array}{c}0.00633 \\
(0.00)\end{array}$ \\
\hline Coach Tenure with Team & $\begin{array}{l}0.109 \\
(0.19)\end{array}$ \\
\hline (Coach Tenure with Team) $^{2}$ & $\begin{array}{c}-0.0283 \\
(0.02)\end{array}$ \\
\hline Coach \% of Wins before Joining Team & $\begin{array}{l}-0.536 \\
(0.49)\end{array}$ \\
\hline Coach \% of Wins with Team & $\begin{array}{l}1.583 \\
(1.15)\end{array}$ \\
\hline No Experience with Current Team Prior to This Year & $\begin{array}{l}0.407 \\
(0.54)\end{array}$ \\
\hline Joined the Team during Mid Year & $\begin{array}{l}0.234 \\
(0.67)\end{array}$ \\
\hline Games Played & $\begin{array}{r}0.0102 \\
(0.02)\end{array}$ \\
\hline Team Participated in Playoffs Last Season & $\begin{array}{l}-0.63 \\
(0.40)\end{array}$ \\
\hline Number of Previous Season Playoff Wins & $\begin{array}{l}-0.018 \\
(4.62)\end{array}$ \\
\hline Number of Games Coached This Season & $\begin{array}{c}0.00444 \\
(0.02)\end{array}$ \\
\hline Difference between Current Record and Previous Year Record & $\begin{array}{r}-0.569^{*} \\
(0.25)\end{array}$ \\
\hline Coach Games x Difference between Current Record and Previous Year Record & $\begin{array}{r}-0.0247^{*} \\
(0.01)\end{array}$ \\
\hline Probability of Team to Get to Playoffs & $\begin{array}{l}0.0346 \\
(0.23)\end{array}$ \\
\hline $\mathrm{N}$ & 26,982 \\
\hline Adjusted $R^{2}$ & 0.333 \\
\hline
\end{tabular}


Table 4 - Predicting Playoff Participation Based on

Current Conference Ranking

(Dependent Variable - Team Went to Playoffs)

(1)

Went To Playoffs

\begin{tabular}{ll}
\hline Conference Rank & $-0.123^{* * *}$ \\
$(0.021)$
\end{tabular}

Games Played $0.00505^{* *}$

Distance from $8 \quad 0.0627^{*}$

(0.025)

Games Played × Distance from $8 \quad 0.00246^{* * *}$

(0.001)

\begin{tabular}{ll}
\hline $\mathrm{N}$ & 30,536
\end{tabular}

Count $R^{2} \quad 0.86$

Adj. Count $R^{2} \quad 0.70$

Notes: The table reports the marginal effects from a Probit regression, where the dependent variable indicates whether the team qualified for the playoffs by the end of the season. Distance from 8 indicates the difference in wins between the team and the eighth-ranked team in the same conference; Games Played $x$ Distance from 8 is an interaction term. All other covariates are as previously defined. Robust standard errors are reported in parentheses and clustered at the team level. ***, **,* indicate statistical significance at the $0.01,0.05$, and 0.10 levels, respectively. 
Table 5: Coach Termination Risk and Rookie Participation during 1999 CBA (Dependent Variable - Played)

\begin{tabular}{|c|c|c|}
\hline & $\begin{array}{c}(1) \\
\text { No Bootstrap }\end{array}$ & $\begin{array}{c}\text { (2) } \\
\text { Bootstrapped s.e.'s }\end{array}$ \\
\hline Termination Risk & $\begin{array}{c}-0.321^{* * *} \\
(0.113)\end{array}$ & $\begin{array}{c}-0.321^{* * *} \\
(0.120)\end{array}$ \\
\hline Draft Rank & $\begin{array}{c}-0.0124^{* * *} \\
(0.003)\end{array}$ & $\begin{array}{c}-0.0124^{* * *} \\
(0.003)\end{array}$ \\
\hline Center & $\begin{array}{l}-0.104^{*} \\
(0.056)\end{array}$ & $\begin{array}{l}-0.104^{*} \\
(0.056)\end{array}$ \\
\hline Forward & $\begin{array}{l}-0.0377 \\
(0.033)\end{array}$ & $\begin{array}{l}-0.0377 \\
(0.033)\end{array}$ \\
\hline Foreigner & $\begin{array}{l}-0.0115 \\
(0.065)\end{array}$ & $\begin{array}{l}-0.0115 \\
(0.066)\end{array}$ \\
\hline Skipped College & $\begin{array}{l}-0.0492 \\
(0.073)\end{array}$ & $\begin{array}{l}-0.0492 \\
(0.074)\end{array}$ \\
\hline College Years & $\begin{array}{l}0.0142 \\
(0.019)\end{array}$ & $\begin{array}{l}0.0142 \\
(0.020)\end{array}$ \\
\hline Traded & $\begin{array}{l}0.191^{* *} \\
(0.085)\end{array}$ & $\begin{array}{l}0.191^{* *} \\
(0.089)\end{array}$ \\
\hline Team Record & $\begin{array}{c}-0.000562 \\
(0.001)\end{array}$ & $\begin{array}{c}-0.000562 \\
(0.001)\end{array}$ \\
\hline Opponent Team Record & $\begin{array}{c}-0.0004^{* * *} \\
0.000\end{array}$ & $\begin{array}{c}-0.0004^{* * *} \\
0.000\end{array}$ \\
\hline Game Number & $\begin{array}{l}-0.00319^{* * *} \\
(0.001)\end{array}$ & $\begin{array}{l}-0.00319^{* * *} \\
(0.001)\end{array}$ \\
\hline Same Conference & $\begin{array}{l}-0.0145 \\
(0.010)\end{array}$ & $\begin{array}{l}-0.0145 \\
(0.010)\end{array}$ \\
\hline Home Team & $\begin{array}{l}0.0101^{* *} \\
(0.005)\end{array}$ & $\begin{array}{l}0.0101^{* *} \\
(0.005)\end{array}$ \\
\hline Rookie's PER Relative to Other Players & $\begin{array}{l}0.0036^{* * *} \\
(0.001)\end{array}$ & $\begin{array}{l}0.0036^{* * *} \\
(0.001)\end{array}$ \\
\hline Accumulated Minutes & $\begin{array}{c}0.00025^{* * *} \\
0.000\end{array}$ & $\begin{array}{c}0.00025^{* * *} \\
0.000\end{array}$ \\
\hline Team’s Previous Season Ranking & $\begin{array}{c}-0.0047^{* * *} \\
(0.004)\end{array}$ & $\begin{array}{c}-0.0047^{* * *} \\
(0.005)\end{array}$ \\
\hline Constant & $\begin{array}{l}0.978^{* * *} \\
(0.116)\end{array}$ & $\begin{array}{l}0.978^{* * *} \\
(0.119)\end{array}$ \\
\hline $\begin{array}{l}\mathrm{N} \\
\text { Adj. } R^{2}\end{array}$ & $\begin{array}{c}12,751 \\
0.322\end{array}$ & $\begin{array}{c}12,751 \\
0.322\end{array}$ \\
\hline \multicolumn{3}{|c|}{$\begin{array}{l}\text { Notes: The table reports estimation results of a linear probability model. Regressions include coach and } \\
\text { team fixed effects. Termination Risk is the predicted probability of coach termination (based on the } \\
\text { regression in Table 3). All other independent variables are defined as before. Standard errors (s.e.'s) are } \\
\text { clustered by player and are reported in parentheses. In column (1) s.e.'s are not corrected for the fact that } \\
\text { Termination Risk is a regression-prediction variable, and in column (2) s.e.'s are corrected using the } \\
\text { bootstrap procedure described in the body of the text. }{ }^{* * *}, * *, * \text { indicate statistical significance at the } 0.01 \text {, } \\
0.05 \text {, and } 0.10 \text { levels, respectively. }\end{array}$} \\
\hline
\end{tabular}


Table 6: Termination Risk and Game Importance -Rookies during the 1999 CBA (Dep. Variable - Played)

\begin{tabular}{|c|c|c|c|c|}
\hline & $\begin{array}{c}(1) \\
\text { No Bootstrap }\end{array}$ & $\begin{array}{c}\text { (2) } \\
\text { Bootstrapped s.e.'s }\end{array}$ & $\begin{array}{c}\text { (3) } \\
\text { No Bootstrap }\end{array}$ & $\begin{array}{c}\text { (4) } \\
\text { Bootstrapped s.e.'s }\end{array}$ \\
\hline Termination Risk & & & $\begin{array}{l}-0.189 \\
(0.128)\end{array}$ & $\begin{array}{l}-0.189 \\
(0.136)\end{array}$ \\
\hline Game Importance & $\begin{array}{c}-0.27 \\
(0.247)\end{array}$ & $\begin{array}{c}-0.27 \\
(0.250)\end{array}$ & $\begin{array}{c}0.121 \\
(0.284)\end{array}$ & $\begin{array}{c}0.121 \\
(0.301)\end{array}$ \\
\hline Termination Risk $\times$ Game Importance & & & $\begin{array}{l}-3.065^{* * *} \\
(1.161)\end{array}$ & $\begin{array}{l}-3.065^{* *} \\
(1.264)\end{array}$ \\
\hline Draft Rank & $\begin{array}{c}-0.0117^{* * *} \\
(0.003)\end{array}$ & $\begin{array}{c}-0.0117^{* * *} \\
(0.003)\end{array}$ & $\begin{array}{c}-0.0121^{* * * *} \\
(0.003)\end{array}$ & $\begin{array}{c}-0.0121^{* * *} \\
(0.003)\end{array}$ \\
\hline Center & $\begin{array}{l}-0.0843 \\
(0.056)\end{array}$ & $\begin{array}{l}-0.0843 \\
(0.056)\end{array}$ & $\begin{array}{l}-0.109^{*} \\
(0.056)\end{array}$ & $\begin{array}{l}-0.109^{*} \\
(0.056)\end{array}$ \\
\hline Forward & $\begin{array}{l}-0.0283 \\
(0.033)\end{array}$ & $\begin{array}{l}-0.0283 \\
(0.033)\end{array}$ & $\begin{array}{l}-0.0311 \\
(0.033)\end{array}$ & $\begin{array}{l}-0.0311 \\
(0.033)\end{array}$ \\
\hline Foreigner & $\begin{array}{l}-0.021 \\
(0.070)\end{array}$ & $\begin{array}{l}-0.021 \\
(0.070)\end{array}$ & $\begin{array}{c}-0.00855 \\
(0.065)\end{array}$ & $\begin{array}{c}-0.00855 \\
(0.067)\end{array}$ \\
\hline Skipped College & $\begin{array}{l}-0.0622 \\
(0.074)\end{array}$ & $\begin{array}{l}-0.0622 \\
(0.074)\end{array}$ & $\begin{array}{l}-0.0448 \\
(0.072)\end{array}$ & $\begin{array}{l}-0.0448 \\
(0.073)\end{array}$ \\
\hline College Years & $\begin{array}{l}0.0113 \\
(0.020)\end{array}$ & $\begin{array}{l}0.0113 \\
(0.020)\end{array}$ & $\begin{array}{l}0.0156 \\
(0.019)\end{array}$ & $\begin{array}{l}0.0156 \\
(0.019)\end{array}$ \\
\hline Traded & $\begin{array}{c}0.13 \\
(0.089)\end{array}$ & $\begin{array}{c}0.13 \\
(0.089)\end{array}$ & $\begin{array}{l}0.190^{* *} \\
(0.086)\end{array}$ & $\begin{array}{l}0.190^{* *} \\
(0.090)\end{array}$ \\
\hline Team Record & $\begin{array}{c}-0.000162 \\
(0.001)\end{array}$ & $\begin{array}{c}-0.000162 \\
(0.001)\end{array}$ & $\begin{array}{c}-0.000484 \\
(0.001)\end{array}$ & $\begin{array}{c}-0.000484 \\
(0.001)\end{array}$ \\
\hline Opponent Team Record & $\begin{array}{c}-0.000402^{* * *} \\
0.000\end{array}$ & $\begin{array}{c}-0.000402^{* * *} \\
0.000\end{array}$ & $\begin{array}{c}-0.000394^{* * *} \\
0.000\end{array}$ & $\begin{array}{c}-0.000394^{* * *} \\
0.000\end{array}$ \\
\hline Game Number & $\begin{array}{c}-0.00295^{* * *} \\
(0.001)\end{array}$ & $\begin{array}{c}-0.00295^{* * *} \\
(0.001)\end{array}$ & $\begin{array}{c}-0.00340^{* * *} \\
(0.001)\end{array}$ & $\begin{array}{c}-0.0034^{* * *} \\
(0.001)\end{array}$ \\
\hline Same Conference & $\begin{array}{l}-0.0157 \\
(0.010)\end{array}$ & $\begin{array}{l}-0.0157 \\
(0.010)\end{array}$ & $\begin{array}{l}-0.0155 \\
(0.010)\end{array}$ & $\begin{array}{l}-0.0155 \\
(0.011)\end{array}$ \\
\hline Home Team & $\begin{array}{l}0.0102^{* *} \\
(0.005)\end{array}$ & $\begin{array}{l}0.0102^{* *} \\
(0.005)\end{array}$ & $\begin{array}{r}0.00942^{*} \\
(0.005)\end{array}$ & $\begin{array}{r}0.00942^{*} \\
(0.005)\end{array}$ \\
\hline Rookie’s PER Relative to Teammates & $\begin{array}{c}0.00349^{* * *} \\
(0.001)\end{array}$ & $\begin{array}{c}0.00349^{* * *} \\
(0.001)\end{array}$ & $\begin{array}{c}0.00353^{* * *} \\
(0.001)\end{array}$ & $\begin{array}{c}0.00353^{* * *} \\
(0.001)\end{array}$ \\
\hline Rookie's Accumulated Minutes & $\begin{array}{c}0.000256^{* * *} \\
0.000\end{array}$ & $\begin{array}{c}0.000256^{* * *} \\
0.000\end{array}$ & $\begin{array}{c}0.000248^{* * *} \\
0.000\end{array}$ & $\begin{array}{c}0.000248^{* * *} \\
0.000\end{array}$ \\
\hline Team's Previous Season Ranking & $\begin{array}{c}-0.000658^{* * *} \\
(0.004)\end{array}$ & $\begin{array}{c}-0.000658^{* * *} \\
(0.004)\end{array}$ & $\begin{array}{c}-0.00379^{* * *} \\
(0.004)\end{array}$ & $\begin{array}{c}-0.00379^{* * *} \\
(0.005)\end{array}$ \\
\hline $\mathrm{N}$ & 12,751 & 12,751 & 12,751 & 12,751 \\
\hline Adj. $R^{2}$ & 0.317 & 0.318 & 0.325 & 0.325 \\
\hline
\end{tabular}

Notes: The table reports estimation results of linear probability models. All regressions include coach and team fixed effects. Standard errors are clustered by player and reported in parentheses. ***, **, * indicate statistical significance at the $0.01,0.05$, and 0.10 levels, respectively. 
Table 7: Robustness Tests - Different Choices of Fixed-Effects for Rookies during the 1999 CBA (Dependent Variable - Played)

\begin{tabular}{|c|c|c|c|c|}
\hline & (1) & (2) & (3) & (4) \\
\hline \multirow{3}{*}{ Fixed Effect } & Team and & Team and & Team, & Player \\
\hline & Coach & Season & Coach and & \\
\hline & & & Season & \\
\hline \multirow[t]{2}{*}{ Termination Risk } & -0.189 & 0.0438 & -0.169 & -0.122 \\
\hline & $(0.136)$ & $(0.076)$ & $(0.149)$ & $(0.104)$ \\
\hline \multirow[t]{2}{*}{ Game Importance } & 0.121 & 0.0545 & 0.0888 & -0.109 \\
\hline & $(0.301)$ & $(0.319)$ & $(0.302)$ & $(0.276)$ \\
\hline \multirow[t]{2}{*}{ Termination Risk $\times$ Game Importance } & $-3.065^{* *}$ & $-2.994^{* *}$ & $-2.920^{* *}$ & $-1.767^{*}$ \\
\hline & $(1.264)$ & (1.297) & $(1.251)$ & $(1.015)$ \\
\hline $\mathrm{N}$ & 12,751 & 12,751 & 12,751 & 12,751 \\
\hline Adj. $R^{2}$ & 0.325 & 0.278 & 0.327 & 0.444 \\
\hline \multicolumn{5}{|c|}{$\begin{array}{l}\text { Notes: The table reports estimation results of linear probability models with different choices of fixed effects. All } \\
\text { specifications include the entire list of controls as in Table } 6 \text {, though not reported. All standard errors are clustered by } \\
\text { player and corrected using the bootstrap procedure described in the text. They are reported in parentheses. }{ }^{* *}, * * \text {, * }\end{array}$} \\
\hline
\end{tabular}


Table 8: Rookie, Second-Year Player, and Veteran Performance

\begin{tabular}{lcccc}
\hline Experience Group & $\begin{array}{c}\text { Mean PER } \\
\text { (Season Level) }\end{array}$ & S.D. & $\mathrm{N}$ & $\begin{array}{c}\text { P-value: } \\
\text { Compared with } \\
\text { Second-Year } \\
\text { Players }\end{array}$ \\
\hline Rookies & $11.709 * * *$ & 4.603 & 277 & 0.004 \\
Second-Year Players & 12.858 & 4.673 & 266 & \\
Veteran & 12.657 & 6.278 & 4,319 & 0.608
\end{tabular}

Notes: The sample includes all active players under a full-year contract. Top three drafted players are excluded from the sample. $* * *, * *, *$ indicate statistical significance at the $0.01,0.05$, and 0.10 levels, respectively.

Table 9: Settings where Termination Risk Is Not Associated with Lower Rookie Use (Dependent Variable - Played)

\begin{tabular}{|c|c|c|c|}
\hline \multirow[t]{5}{*}{ CBA } & 2005 & 1999 & 2005 \\
\hline & (1) & (2) & (3) \\
\hline & Rookies & Second & Second \\
\hline & & Year & Year \\
\hline & & Players & Players \\
\hline \multirow[t]{2}{*}{ Termination Risk } & -0.025 & 0.165 & -0.00226 \\
\hline & $(0.169)$ & $(0.157)$ & $(0.119)$ \\
\hline \multirow[t]{2}{*}{ Game Importance } & 0.0306 & 0.353 & -0.0677 \\
\hline & $(0.373)$ & $(0.309)$ & $(0.450)$ \\
\hline \multirow[t]{2}{*}{ Termination Risk $\times$ Game Importance } & 0.862 & $(0.447)$ & 0.409 \\
\hline & $(1.219)$ & $(1.091)$ & $(1.248)$ \\
\hline $\mathrm{N}$ & 10,912 & 12,042 & 9,930 \\
\hline Adj. $R^{2}$ & 0.215 & 0.226 & 0.253 \\
\hline \multicolumn{4}{|c|}{$\begin{array}{l}\text { Notes: The table reports estimation results of linear probability models with different samples of } \\
\text { player years and CBAs. All specifications include coach and team fixed effects, in addition to the } \\
\text { entire list of controls as in Table } 6 \text {, though not reported. Standard errors are clustered by player } \\
\text { and corrected using the bootstrap procedure described in the text. They are reported in } \\
\text { parentheses. }{ }^{* *}, *^{* *}, * \text { indicate statistical significance at the } 0.01,0.05 \text {, and } 0.10 \text { levels, } \\
\text { respectively. }\end{array}$} \\
\hline
\end{tabular}


Table 10: Pooled Regressions for 1999 \& 2005 CBA (Dep. Variable - Played)

\begin{tabular}{|c|c|c|}
\hline & $\begin{array}{c}\text { (1) } \\
\text { Rookies }\end{array}$ & $\begin{array}{c}(2) \\
\text { Second Year } \\
\text { Players }\end{array}$ \\
\hline CBA_05 & $\begin{array}{l}-0.0282 \\
(0.043)\end{array}$ & $\begin{array}{l}0.0394 \\
(0.034)\end{array}$ \\
\hline Termination Risk & $\begin{array}{l}-0.0561 \\
(0.115)\end{array}$ & $\begin{array}{c}0.109 \\
(0.135)\end{array}$ \\
\hline CBA_05 $\times$ Termination Risk & $\begin{array}{l}0.0901 \\
(0.167)\end{array}$ & $\begin{array}{l}-0.0932 \\
(0.151)\end{array}$ \\
\hline Game Importance & $\begin{array}{c}0.257 \\
(0.298)\end{array}$ & $\begin{array}{c}0.24 \\
(0.286)\end{array}$ \\
\hline CBA_05 × Game Importance & $\begin{array}{l}-0.467 \\
(0.454)\end{array}$ & $\begin{array}{l}-0.400 \\
(0.484)\end{array}$ \\
\hline Termination Risk $\times$ Game Importance & $\begin{array}{l}-4.111^{* * *} \\
(1.315)\end{array}$ & $\begin{array}{l}-0.388 \\
(1.068)\end{array}$ \\
\hline $\begin{array}{l}\text { CBA_05 × Termination Risk } \times \\
\text { Game Importance }\end{array}$ & $\begin{array}{l}5.571^{* * *} \\
(1.787)\end{array}$ & $\begin{array}{c}1.282 \\
(1.547)\end{array}$ \\
\hline $\begin{array}{l}\mathrm{N} \\
\text { Adj. } R^{2}\end{array}$ & $\begin{array}{c}23,663 \\
0.263\end{array}$ & $\begin{array}{c}21,972 \\
0.222\end{array}$ \\
\hline $\begin{array}{l}\text { Notes: The table reports estimation results of l } \\
\text { of player years and draft ranking groups. Al } \\
\text { effects, in addition to the entire list of controls } \\
\text { dummy variable indicating if the rookie cont } \\
\text { (1999 CBA, otherwise). Standard errors are } \\
\text { bootstrap procedure described in the text. They } \\
\text { statistical significance at the } 0.01,0.05 \text {, and } 0.1\end{array}$ & $\begin{array}{l}\text { cability mo } \\
\text { ble } 6 \text {, though } \\
\text { inder the co } \\
\text { d by playe } \\
\text { orted in pare }\end{array}$ & $\begin{array}{l}\text { th different samples } \\
\text { ach and team fixed } \\
\text { ported. CBA_05 is a } \\
\text { s of the } 2005 \text { CBA } \\
\text { corrected using the } \\
* * *, * *, * \text { indicate }\end{array}$ \\
\hline
\end{tabular}

